the life-history includes two or even three completed sexual cycles, the $30 \rightleftharpoons 60,60 \rightleftharpoons 120$ and $45-50 \rightleftharpoons 90$. Whether or not they are closed independent cycles cannot be decided on the evidence at present available. Should they be independent, the evolutionary implications would be all the greater. In $P$. elegans, on the other hand, the life-history includes only one completed sexual cycle and the triploid appears to be a 'dead-end' from the evolutionary point of view.

Thus, while agreeing with Prof. Barber up to a point, I have endeavoured to show that life-histories in the algæ are conditioned by non-genetic as well as genetic factors, and that, until more data are available, some restraint in applying genetical concepts based on the higher plants should be exercised.

$I$ am also making a plea for wider and more ex. tensive studies of the life-histories in the various classes of algæ. It is now recognized that while the Hofmeisterian cycle provides an adequate account of the life-history of Bryophyta, Pteridophyta and Spermatophyta, it does not suffice to describe the many types of life-history to be found in the algæ. A knowledge of morphology, physiology and cytology as well as of genetics is necessary for an analysis of the factors conditioning the life-histories in this group of plants and for an understanding of how the gametophyte-sporophyte cycles of the higher plants arose.

${ }^{1}$ Barber, H. N., Australian J. Sci., 9, 217 (1947).

'Drew, K. M., Ann. Bot., 48, 549 (1934).

${ }^{3}$ Drew, K. M., Ann. Bot., N.S., 7, 23 (1943).

- Drew, K. M., Ann. Bot., N.S., 3, 347 (1939).

s Svedelius, N., Ber. deutsch. Bot. Ges.. 32, 106 (1914).

- Sharp, L. W., La Cellule, 85, 193 (1925).

'Drew, K. M., Ann. Bot., N.S., 1, 463 (1937).

${ }^{8}$ Pringsheim, E. G., "Pure Cultures of Algæ" (Cambridge, 1946).

"Hartmann, M., "Die Sexualität" (Jena, 1943).

${ }^{10}$ Drew, K. M., Biol. Rev., 19, 105 (1944).

\section{BIOCHEMICAL REACTIONS OF CHEMICAL WARFARE AGENTS}

$\mathrm{T}$

HE true nature of Greek Fire is still wrapped in mystery and it is difficult to decide whether its use constituted chemical warfare. Chemical warfare, as we know it, was employed only in the First World War (1914-18), when mustard gas and phosgene were used and the study of their pathology was commenced. Work on the nature of these agents proceeded slowly from 1920 until 1939, when there was increased interest in poison gas. Since the Second World War ended, some of the work which was carried out for the British and American Govern." ments has been released, or 'declassified' as the Americans say, and been published. The Biochemical Society arranged a symposium held at the London School of Hygiene and Tropical Medicine on some aspects of the biochemistry of these substances on December 13.

In introducing the symposium, Dr. Malcolm Dixon described how much of the biochemical research work was carried out by three extra-mural teams under Prof. R. A. Peters at Oxford, Prof. A. Wormall of St. Bartholomew's Hospital, London, and himself at Cambridge. Similar teams had worked on the problems in the United States. Much of the matter has interest apart from the original purpose of the investigations. In fact, many of the substances developed for use in the event of chemical warfare have found direct peace-time applications. Examples of this include the British anti-lewisite (B.A.L.), a general remedy for arsenical poisoning; disopropylfluorophosphonate (D.F.P.), which is being used as a parasympathomimetic drug in treatment of myasthenia gravis; and methyl bis( $\beta$-chloroethyl)amine or nitrogen mustard, used in palliation of Hodgkin's disease.

\section{Chemical Reactions of Mustard Gas}

Dr. A. G. Ogston gave the first paper of the symposium, dealing with "The Reactions of Mustard Gas in Aqueous Solution". Earlier work, starting with that of R. A. Peters and E. Walker (Biochem. J., $17,260 ; 1923)$, on the kinetics of the hydrolysis of mustard gas in water had shown that the reactions of hydrolysis and substitution are of the ' $\mathrm{SN}_{1}$ ' type described by Ingold. The initial reaction appears to be an activation process of the first order. The activated form can then undergo a number of different second-order reactions with different substances. The secondary reactions compete with each other, so that the final products depend upon the concentrations and velocity constants of reactions of the substituting reagents present. Mustard gas can combine with almost all chemically reactive groups of biological systems. The differences in velocity constants of the activated molecules for reaction with different substances or groups can be expressed by means of competition factors. Thus thiophosphonates which react readily with mustard gas have high competition factors. Substances with high competition factors were tried as therapeutic agents for mustard gas poisoning, but were not very effective. The reaction of mustard gas, $\beta \beta$-dichloroethyl sulphide, with water leads first to the half-hydrolysis product, $\beta$-hydroxyethyl $\beta$-chloroethyl sulphide, and then to thiodiglycol. The half-hydrolysis product has only one tenth of the toxicity of mustard gas.

Dr. J. C. Boursnell discussed the reaction of mustard gas with proteins. Early work had shown that mustard gas reacts with horse serum to give a new antigen, that it inactivates enzymes and combines with kerateine to give a product with increased chlorine and sulphur content (R. A. Peters). The free amino-groups of proteins react in alkaline solution; but other groups must also react, as the phenylisocyanate derivatives of proteins in which the amino-groups are blocked still combine with vesicants. The protein carboxyl groups also react to give alkali labile derivatives, and nutritional studies with proteins treated with mustard gas have indicated that histidine, lysine, methionine and threonine residues have reacted. Nucleoproteins react to give insoluble derivatives with high sulphur and phosphorus content (I. Berenblum and R. Schoental, Nature, 159, 727 ; 1947). Studies with mustard gas containing radioactive sulphur $\left(\mathrm{S}^{35}\right)$ have shown that when the material is injected intravenously into rabbits most of the sulphur is fixed in the lungs and kidney, but pathological studies show that these organs are not seriously damaged by the vesicant.

\section{Effects of Mustard Gas on Enzymes and Tissues}

Dr. D. M. Needham described some of the work on the effect of mustard gas on enzymes and tissues. A brief account of this aspect of the subject has already appeared in Nature (M. Dixon and D. M. Needham, Nature, 158, 432; 1946). Of a large number of enzymes subjected to the action of mustard gas in low concentrations, only the phosphokinases and some proteinases are markedly 
inhibited. Of the phosphokinases, hexokinase was the first to be examined, and it is probably due to inhibition of this enzyme and deuterohexokinase that the glycolysis of tissues is inhibited by vesicants. Hexokinase is a sulphydryl enzyme, but the inactivation by mustard gas appears to be due to reaction with other groups than the sulphydryl group. When hexokinase is inactivated, five or six molecules of mustard gas react with each molecule of the enzyme. Hexokinase is inhibited in the skin of animals treated with mustard gas, and this effect may be the fundamental cause of the pathological changes. Creatine phosphokinase is even more sensitive to mustard gas when tested in vitro but is not inhibited in tissues of animals treated with the vesicant.

\section{British Anti-Lewisite}

The development of British anti-lewisite (B.A.L.), which is a product of the Biochemical Laboratory at Oxford, was outlined by Dr. R. H. S. Thompson (cf. R. A. Peters, L. A. Stocken and R. H. S. Thompson, Nature, 156,616 ; 1945). Early work carried out at Oxford (E. Walker, Biochem. J., 22, 292 ; 1928) and in the United States showed that arsenicals reacted readily with SH groups of glutathione or of proteins. Sodium arsenite and the arsenical vesicant, lewisite, poison the pyruvic acid oxidase system of brain tissue, and the blood of animals poisoned with arsenicals has a high concentration of pyruvate analogous to that occurring in thiamine deficiency.

The pyruvic oxidase system was used as an in vitro test for substances which would neutralize the toxicity of arsenicals. Study of the reaction of arsenicals with kerateine showed that each atom of arsenic reacted with two SH groups of the protein. Monothiol compounds had no effect in neutralizing arsenical poisoning, but a number of dithiols were effective. Of the latter, 2 : 3-dimercaptopropanol was the most suitable, and proved to be an efficient antidote both when tested in vitro with the pyruvate oxidase system and in vivo against the vesicant action of lewisite on human skin and against the toxic action in animals and men. This compound was called 'British Anti-Lewisite' (B.A.L.), and it is now used clinically in treatment of arsenical dermatitis. Dr. Thompson suggested that sulphydryl enzymes might be divided into two classes: (a) those which are protected by monothiols, as are choline esterase and hexokinase; and (b) those which require dithiols, as do pyrophosphatase and pyruvate oxidase. It is possible that members of the second class require two thiol groups in close proximity for their action, whereas those of the first group need only one thiol group.

\section{Lachrymators}

Dr. M. Dixon, in describing the reactions of lachry. mators with enzymes and proteins, showed how most lachrymators fall into three classes: the active ('positive') halogen compounds, unsaturated compounds and arsenicals. All lachrymators of these classes poison sulphydryl enzymes, and this suggested that the lachrymators react with sulphydryl residues. Many different experiments showed this to be the case, and the lachrymators are specific reagents for identifying sulphydryl enzymes. The active halogencontaining lachrymators can be used for the manometric estimation of sulphydryl groups as they react rapidly, giving acid proportional to the sulphydryl groups present.

\section{Alkyl Fluorophosphonates}

The alkyl fluorophosphonates are highly toxic substances, first made by Dr. B. C. Saunders and shown by Prof. E. D. Adrian and Dr. W. Feldberg and by Dr. Mackworth to be inhibitors of choline esterase. Dr. E. C. Webb discussed the nature of this inhibition, which is non-competitive and not reversed by dialysis. Eserine also inhibits choline esterase, but such inhibition is competitive (being reduced by increase in concentration of the sub. strate, acetylcholine) and reversible on dialysis. These new compounds are very potent. Thus horse serum choline esterase (that is, pseudo-choline esterase) is inhibited to the extent of 50 per cent by $1.3 \times 10^{-9} M$ diisopropylfluorophosphonate. Such fluorophosphonates poison other esterases, such as liver esterase. In addition to the fluorophosphonates, hexaethyltetraphosphate and tetraethylpyrophosphate, which were introduced as insecticides, have been found to be extremely potent poisons of choline esterase.

\section{'Nitrogen Mustards'}

The pharmacology of the chloroethylamines, to which class the 'nitrogen mustards' belong, was described by Dr. E. Boyland. The nitrogenous vesicants, which are poly( $\beta$-chloroethyl)amines, have many properties similar to mustard gas. Study of these substances led to the discovery of interesting pharmacological properties in related compounds. Dimethyl- $\beta$-chloroethylamine, on injection into animals, causes prolonged partial paralysis, so that treated mice have the appearance of waltzing mice. Dibenzyl- $\beta$-chloroethylamine (known as 'dibenamine') antagonizes and reverses the action of adrenaline on the blood pressure. The alkyl bis ( $\beta$-chloroethyl)amines are very toxic substances and potent vesicants. The best known of these is methyl bis ( $\beta$-chloroethyl)amine (HN2). These chloroethylamines are very reactive and combine with many tissue constituents and with water to produce a series of products. One of the hydrolysis products, which has been identified as $\beta$-hydroxyethyl methyl ethyleneimonium chloride, causes partial paralysis and rapid death of mice, with convulsions. The poly( $\beta$-chloroethyl)amines are also of interest because, like mustard gas, they are radiomimetic poisons-many of their effects resemble those produced by ionizing radiations. Such effects include vesication, death following hæmoconcentration due to loss of fluid by diarrhœe and vomiting, particularly severe damage to the intestinal tract, bone marrow and lymphoid tissue, resulting in reductions in the concentrations of circulating leucocytes and platelets. Both kinds of agent have similar effects on cell nuclei, causing stickiness of nuclei and chromosome breaks. They have been shown to induce mutations in Drosophila, Neurospora and Escherichia coli. Both the vesicants and radioactive material cause greying of the hair of coloured mice without preventing the growth of the hair. The poly( $\beta$ chloroethyl)amines have been used clinically as alternatives to radiotherapy in the treatment of leukæmia, Hodgkin's disease and bronchogenic carcinoma. One of the drawbacks to the treatment is the nausea and vomiting caused, which are similar to radiation sickness. The similarity in effects of vesicants and radiations suggests that the study of the action of vesicants may lead to increased knowledge of the mechanism of the biological action of radiations. 
At the conclusion of the symposium, Prof. R. A. Peters expressed the view that the investigations on war gases which had been started should be carried to their conclusion. $\mathrm{He}$ thought that biochemistry owed a debt to the Ministry of Supply, and particularly to Mr. J. Davidson Pratt and Mr. L. T. D. Williams, for their encouragement of biochemical investigations into these particular war-time projects. Much of the research has given us knowledge which is of both academic interest and practical value in peace-time.

E. BOYLAND

\section{REPRODUCTION OF PHOTO- GRAPHICALLY RECORDED OSCILLOGRAPH SIGNALS}

\section{By R. L. F. BOYD \\ Dept. of Mathematics, University College, London*}

$\mathrm{T}$ HE practice of recording the secular variation of an E.M.F. signal, representing some physical variable, by photographing an oscillograph screen on a moving film, is now common to almost every branch of applied science ; in the past decade, many thousands of feet of film have been so used in the study of an ever-increasing variety of problems. Doubtless the versatility of the cathode ray oscilloscope is at the same time the raison d'être and the sine qua non for this ubiquity, not the least of its good qualities being its robustness and ability to continue operating under conditions which would preclude other methods.

Frequently it is required to analyse the oscillograph film record in some detail : the peak, mean, or root mean square values of the wave may be required, the Fourier components, or the value of certain ordinates and their corresponding abscissæ. Often, too, the analysis is of such a nature that it could most readily be carried out by electronic methods, as when the operation to be performed is a function of a differential operator. In view of these considerations, especially in the study of mechanical vibrations, it became evident that a means of recon verting the oscillograph record into an E.M.F. sigmal would be of value, and accordingly experiments were undertaken which resulted in the production of the curve follower described here.

The development of the instrument was both a test of the applicability of the principle employed to the general requirements enumerated above, and an attempt to meet a specialized need for a means of reproducing certain records containing frequencies from zero to about $200 \mathrm{c} . / \mathrm{s}$. Before the work was commenced, however, careful consideration was given to the possibility of employing one or other of the conventional means of acoustic reproduction (if necessary, using a frequency modulated system), such as sound-on-film or disk, or magnetic tape, and in this connexion special importance was attached to the following factors: the size and ruggedness of the recording equipment; its ability to operate in the presence of mechanical vibrations of acceleration magnitude several times that of gravity; its frequency response; and the reliability with which the original signal could be systematically and continuously reproduced. Direct reproduction from an

* Formerly at Admiralty Mining Establishment, Havant. oscillograph record offered a number of advantages : the recording apparatus is readily portable and insensitive to mechanical vibrations, consisting only of the standard laboratory type of oscilloscope and camera; and, moreover, visual observation of the signal can be carried out directly both from the record or from the tube sereen. The frequency response of the reproducing equipment is constant down to D.C., a reading of the ordinate being obtained on a voltmeter plugged into the output whether the film is or is not in motion. The output-level is high without amplification (of the order of tens of volts) and is insensitive to changes in the characteristics of components or to the contrast or gradation of the film ; and, moreover, it was thought that the method would be of value as an automatic curve follower for feeding analysers with any curve from which a photographic copy or other suitable black-and-white transparency could be made.

The film record, consisting of a clear line trace upon a dark ground, is mounted so as to pass between a lens and a photo-electric cell, while before the lens with its screen focused on the film is a cathode ray tube. A linear 'time-base' moves the cathode ray spot across the screen so that its image scans the film along the ordinate until it reaches the trace, at which instant the sudden change in light entering the photocell produces a pulse which is used to trigger the 'time-base', causing it to restart its sweep from the edge of the record. This process is repeated several thousand times a second, so that the mean voltage on the cathode ray tube deflector plates is a measure of the distance the spot moves from the edge of the record, that is, of the ordinate. Thus, by filtering out the time-base frequency from the sweep voltage, a signal proportional to the ordinate is obtained, and providing the frequency of variation of the signal is less than the scanning frequency by a factor greater than about 5 , there is a faithful reproduction of the record.

In the initial experiments all the electronic circuits apart from the photocell were provided by a commercial type of laboratory oscilloscope (the 4-inch double-beam instrument made by Messrs. Cossor, Ltd.), the sweep voltage being produced by the oscilloscope's own 'time-base', while the amplification of the synchronizing pulse was performed by the deflexion amplifiers of the same instrument, the film being repassed through the camera that was used to make the record after it had been modified to take a photo-electric cell behind the film.

As a result of the success of these experiments and in view of the mechanical and electrical simplicity of the method, it was decided to build the instrument shown in Fig. 1, capable of reproducing continuously a loop recording carried on an aluminium drum $10 \mathrm{ft}$. in circumference. This form of construction was chosen because it completely eliminates wear on the film, and also with the view of using the instrument as the scanning part of an analyser of the type developed by Barber and his colleagues at the Admiralty Research Laboratories ${ }^{1}$. This analyser employs a varying width black-and-white record on photographic paper, mounted on a drum which revolves at a slowly decreasing speed. As the speed falls, each harmonic of the record is in turn brought into resonance with a vibrating galvanometer, from which a signal is obtained providing the Fourier amplitude analysis of the record. The possibility of using such an analyser directly on an oscillograph record is a considerable simplification, and at the 